\title{
PERDAS DE SOLO E ÁGUA POR EROSÃO HÍDRICA INFLUENCIADAS POR MÉTODOS DE PREPARO, CLASSES DE DECLIVE E NÍVEIS DE FERTILIDADE DO SOLO(1)
}

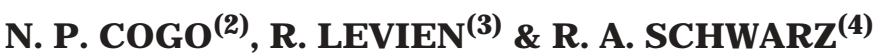

\begin{abstract}
RESUMO
A erosão é a forma mais prejudicial de degradação do solo. Além de reduzir sua capacidade produtiva para as culturas, ela pode causar sérios danos ambientais, como assoreamento e polui ção das fontes de água. Contudo, usando adequados sistemas de manejo do solo e bem planejadas práticas conservacionistas de suporte, os problemas de erosão podem ser satisfatoriamente resolvidos. Com o propósito de obter informações quantitativas sobre o assunto, para servirem de guia nos planejamentos conservacionistas de uso da terra, realizou-se um experimento de erosão sob chuva natural, em Latossolo Vermel ho distroférrico típico textura muito argi losa, no município de Santo Ângelo, região das Missões (RS), de dezembro de 1994 a maio de 1996, objetivando quantificar as perdas de solo e água causadas por erosão hídrica. Os tratamentos consisti ram dos métodos de preparo do solo convencional, reduzido e semeadura direta, avaliados sob as condições "solo com fertilidade corrigida" nas classes de declividade de 0-0,04; 0,04-0,08 e 0,08-0,12 $\mathrm{m} \mathrm{m}^{-1}$ (com gradientes médios de, respectivamente, 0,035; 0,065 e $0,095 \mathrm{~m} \mathrm{~m}^{-1}$ ) e "solo com fertilidade atual" na classe de declividade de $0,04-0,08 \mathrm{~m} \mathrm{~m}^{-1}$. As operações de preparo do solo e semeadura foram efetuadas todas transversalmente ao declive, exceto para o tratamento-testemunha (preparo convencional, sem cultivo, continuamente descoberto e sem crosta), no qual as operações de aração e gradagem foram realizadas no sentido do declive. A seqüência de culturas utilizada na avaliação da erosão foi constituída de dois ciclos culturais de soja (Glycine max, L.), no período de primavera-verão de 1994/ 95 e 1995/96, e um de aveia preta (Avena strigosa, S.), no período de outonoinverno de 1995. O índice de erosividade das chuvas ( $\mathrm{EI}_{30}$ ) calculado no período experimental (1,5 ano) foi de $10.236 \mathrm{MJ} \mathrm{mm} \mathrm{ha}^{-1} \mathrm{~h}^{-1}$ e concentrou-se, repetidamente, em 1995 e 1996, nos meses de janeiro a março, perfazendo, acumuladamente nestes duplos períodos, $70 \%$ do total. Perdas si gnificativas de solo por erosão hídrica (até $80 \mathrm{Mg} \mathrm{ha}^{-1} \mathrm{em}$ um único ciclo cultural) ocorreram somente no preparo convencional sem cultivo e estabelecido no sentido do declive
\end{abstract}

(1) Parte da Tese de M estrado do terceiro autor, apresentada à Faculdade de Agronomia, Universidade Federal do Rio Grande do Sul - FA/UFRGS. Realizada com recursos da FAPERGS. Recebido para publicação em junho de 2002 e aprovado em abril de 2003.

(2) Professor Adjunto do Departamento de Solos, Faculdade de Agronomia, Universidade Federal do Rio Grande do Sul - FA/ UFRGS. Caixa Postal 15.100, CEP 90001-970 Porto Alegre (RS). Bolsista do CNPq. E-mail: neroli@vortex.ufrgs.br

(3) Professor Adjunto do Departamento de Solos, Faculdade de Agronomia, UFRGS. E-mail: renatole@vortex.ufrgs.br

(4) Engenheiro-Agrônomo, Assistente Técnico da EMATER-RS. Rua Botafogo 1051, CEP 90150-053 Porto Alegre (RS). E-mail: ricardo@emater.tche.br 
(testemunha), embora o solo na parcela tenha apresentado um valor de erodibilidade muito baixo (fator $\mathrm{K}$ igual a $0,0091 \mathrm{Mg}^{\text {ha }} \mathrm{h} \mathrm{MJ}^{-1} \mathrm{~mm}^{-1} \mathrm{ha}^{-1}$ ). Sob cultivo, porém em valores bem mais baixos, as perdas de solo continuaram sendo as maiores no preparo convencional (ao redor de $13,0 \mathrm{Mg} \mathrm{ha}^{-1} \mathrm{em} \mathrm{1,5}$ ano), notadamente nas classes de declividade média ealta, ficando o preparo reduzi do com as intermediárias (ao redor de 4,0 Mg ha-1 em 1,5 ano) e a semeadura direta com as menores (ao redor de 1,0 $\mathrm{Mg} \mathrm{ha}^{-1} \mathrm{em} \mathrm{1,5}$ ano), enquanto as perdas de água foram todas muito baixas e pouco di ferenciadas. A condição "solo com fertilidade corrigida" aumentou muito a quantidade de fitomassa aérea produzida pelas culturas e, conseqüentemente, a massa de resíduos culturais, a percentagem de cobertura morta do solo e as perdas de solo por erosão hídrica, especialmente no preparo convencional; contudo, ela praticamente não influenciou as perdas de água. Apesar das operações de preparo do solo e semeadura em contorno, fertilidade do solo melhorada e alta resistência do solo à erosão, o sistema de produção aveia preta-soja em preparo convencional apresentou, em declives superiores a $0,04 \mathrm{~m} \mathrm{~m}^{-1}$, perdas anuais de solo por erosão muito próximas ao limite tolerável, já no curto comprimento de rampa de $21 \mathrm{~m}$ utilizado nas parcelas experimentais deste estudo.

Termos de indexação: erosão hídrica, preparo do solo; sistema de cultivo, declividade do solo, fertilidade do solo.

\section{SUMMARY: SOIL AND WATER LOSSES BY RAINFALL EROSION INFLUENCED BY TILLAGE METHODS, SLOPE-STEEPNESS CLASSES, AND SOIL FERTILITY LEVELS}

Erosion is themost de eterious form of soil degradation. Besides reducing theproductivity capacity for crops, it can causeserious environmental problems, such as sedimentation and pollution of water sources. Yet the use of sound soil management systems and wel I-pl anned support conservation practices can solveerosion problems satisfactorily. In order to obtain quantitative information on the subject as guidelines for conservation plans, an erosion experiment under natural rainfall was conducted on a very clayey soil (Typic Haplortox), in Santo Ângelo, region of Missões, Rio Grande do Sul State, Brazil, December 1994 through May 1996, to quantify soil and water losses caused by rainfall erosion. Treatments of conventional tillage, reduced tillage, and no-till were evaluated under conditions of "soil with improved fertility" in slopesteepness classes of 0-0.04, 0.04-0.08, and 0.08-0.12 " m m-1 (with average sl ope gradients of, respectively, 0.035, 0.065, and $0.095 \mathrm{~m} \mathrm{~m}^{-1}$ ) and of "soil with actual fertility" in the $0.04-0.08 \mathrm{~m} \mathrm{~m}^{-1}$ slopesteepness class. A crop sequence of two soybean (Glycine max, L) cycles (spring-summer 1994/ 95 and 1995/ 96) followed by black oat (Avena strigosa, S.) (fall-winter 1995) was used for an evaluation of erosion. Tillage and planting operations were performed along contour lines in all plots, except for the Wischmeier's unit pl ot, wherepl owing and disking operations wereperformed up and down the slope. The cal culated rainfall erosi vity index $\mathrm{EI}_{30}$ of the experimental period (1,5 year) was $10.236 \mathrm{MJ} \mathrm{mm} \mathrm{ha-1} \mathrm{h}^{-1}$. Both in 1995 and 1996 a concentration in the period between $\mathrm{J}$ anuary and March accumulated $70 \%$ of thetotal rainfall. Only under conventional tillage with no cropping and in vertical direction (control plot) thereweregreat soil losses by rai nfall erosion (up to $80 \mathrm{Mg} \mathrm{ha}^{-1}$ in a singlecrop cycle), although thesoil in the plot presented a very low erodibility value ( $\mathrm{K}$-factor of $0.0091 \mathrm{Mg}$ ha h MJ ${ }^{-1} \mathrm{~mm}^{-1} \mathrm{ha}^{-1}$ ). Under cropping, though in much lower values, soil losses wereal so highest in conventional tillage (about $13.0 \mathrm{Mg} \mathrm{ha}^{-1}$ in 1,5 years), markedly in medium and high sl ope-steepness classes. Intermediatesoil losses wereassociated with reduced tillage (about $4.0 \mathrm{Mg} \mathrm{ha}^{-1}$ in 1,5 year), and thel owest with notill (about $1.0 \mathrm{t} \mathrm{ha}^{-1}$ in 1,5 year), whilewater losses wereall very low and littledifferentiated. The condition "soil with improved fertility" greatly increased the crop aerial biomass, consequently thecrop residuemass and, thus, the percentage of mulch covering thesoil and soil loss by rainfall erosion, especially in the conventional tillage, although it did not appreciably affect water losses. In spite of tillage and planting operations al ong contours, improved soil fertility, and a relativehigh resistance of soil to er osi on, the black oat-soybean crop in conventional tillage presented annual soil losses by rainfall erosion that lay very cl oseto thetol erablel evel on slopes steeper than $0.04 \mathrm{~m} \mathrm{~m}^{-1}$, even in theshort slopelength of $21 \mathrm{~m}$ used in the experimental plots of this study.

Index terms: water erosion; soil tillage; cropping system, slope steepness, soil fertility. 


\section{INTRODUÇÃO}

Fundamentalmente, o processo de erosão hídrica do solo pela água da chuva é condicionado pelos fatores chuva, solo, topografia, cobertura e manejo e práticas conservacionistas de suporte (Hudson, 1977). Noestado do Rio Grande do Sul, a erosividade das chuvas concentra-se mais na época de implantação e desenvolvimento das culturas de primavera-verão (Cogo et al., 1978; Lima et al., 1992), o que aumenta o potencial de erosão hídrica nesse período. Em decorrência do uso demétodos de preparo com rel ativa intensa mobil ização do sol o em al gumas regiões, os riscos de erosãosão bastante aumentados.

O uso de métodos de preparo e semeadura com baixo grau de mobilização do solo e com manutenção dos resíduos culturais na superfície e, ou, semiincorporados ao solo (genericamente chamados de "preparos de solo conservacionistas") cresceu expressivamente no Rio Grande do Sul na última década, com predominância do preparo reduzido e sem preparo ou semeadura direta (Farias \& Ferreira, 1996).

A cobertura do sol o proporcionada pel os resíduos culturais deixados na superfície tem ação direta e efetiva na redução da erosão hídrica, em virtude da dissi pação de energia cinética das gotas da chuva, a qual diminui a desagregação das partículas de solo e o selamento superficial e aumenta a infiltração de água. Ela atua ainda na redução da velocidade do escoamento superficial e, conseqüentemente, da capacidade erosiva da enxurrada (Sloneker \& Moldenhauer, 1977; Cogo, 1981). A percentagem de cobertura do solo proporcionada pelas restevas das culturas é fator fundamental na redução das perdas de solo por erosão hídrica (Sloneker \& Moldenhauer, 1977), obtendo-se boa eficácia já com $30 \%$ de cobertura (Cogo, 1981; Lopes et al., 1987). No entanto, a persistência dessa proteção ao solo irá depender do grau de incorporação dos resíduos culturais, bem como do método de preparo e, ou, de semeadura empregado.

Diversas pesquisas têm demonstrado a eficácia dos preparos conservacionistas de solo no controle da erosão, com reduções de 50 a $95 \%$ nas perdas de solo, em relação ao preparo convencional. E, dentre os preparos conservacionistas mais investigados, as perdas de solo na semeadura direta têm, de modo geral, sido menores do que nos preparos reduzidos (Cogo, 1981; Eltz et al., 1984; Rio Grande do Sul, 1985; Santana et al., 1994). No entanto, as perdas de água, de modo geral, têm sido variadas e bem menos influenciadas pela cobertura superficial morta do que as perdas de solo (Cogo, 1981; Bertol et al., 1989; Alves et al., 1995), podendo ser superiores ora na semeadura direta (Vieira et al., 1978), ora no preparo reduzido, ora no preparo convencional (Nunes et al., 1987), ou mesmo semel hantes entre os diferentes métodos de preparo do solo (Bertol, 1994), dependendo de condições, tais como: regime de chuva, tipo de solo, topografia e seqüência/rotação cultural utilizada no sistema global de manejo do solo da propriedade.

A inclinação do declive do terreno é outro fator que influencia fortemente as perdas de solo e água por erosão hídrica, pois, à medida que ela aumenta, aumentam o volume e a velocidade da enxurrada e diminui a infiltração de água no solo. Com isso, aumenta a capacidade de transporte das partículas de solo pela enxurrada, assim como a própria capacidade desta de desagregar solo, por ação de cisalhamento, principalmente quando concentrada nos sulcos direcionados no sentido da pendente do terreno.

O objetivo principal da presente pesquisa foi avaliar as perdas de sol o eágua causadas por erosão hídrica, sob chuva natural, em diferentes métodos de preparo, classes de declive e níveis de fertilidade do solo, num solo muito argiloso situado na região das Missões, RS. De posse dos resultados obtidos após análise, poderão ser feitas recomendações de manejo do sol o que sejam as mais eficazes tanto para a redução da erosão hídrica, quanto para a preservação do ambiente.

\section{MATERIAL E MÉTODOS}

A pesquisa foi realizada na microbacia do rio Lageado Atafona, situada a $10 \mathrm{~km}$ da sede do município de Santo Ângelo, na região das Missões (RS), numa área aproximada de 2,5 ha, em solo Latossolo Vermel ho distroférricotípico (Brasil, 1999) textura muito argilosa $\left(650 \mathrm{~g} \mathrm{~kg}^{-1}\right.$ de argila na camada de $0-20 \mathrm{~cm}$ de profundidade). A área experimental situava-se dentro de uma área maior de lavoura, a qual por anos vinha sendo explorada com a sucessão trigo-soja, sob preparo convencional de sol o (uma aração com arado de discos, seguida de duas ou mais gradagens niveladoras com grade também de discos), encontrando-se bastante degradada, física, química e biologicamente, além de apresentar alto grau de infestação com plantas invasoras no momento da instal ação do experimento.

Os tratamentos avaliados foram três métodos de preparo do solo, estabelecidos em três classes de declividade do terreno e dois níveis de fertilidade do solo, conforme a seguir detal hado.

Os métodos de preparo do solo foram: (a) convencional - uma aração, efetuada com arado, montado, de três discos, reversível, operado à profundidade média de $0,20 \mathrm{~m}$, seguida de duas gradagens niveladoras, efetuadas com grade excêntrica de discos, de arrasto, operada à profundidade média de $0,08 \mathrm{~m}$; (b) preparo reduzido - uma escarificação, efetuada com escarificador, montado, com sete hastes parabólicas munidas de 
ponteiras estreitas, com disco de corte de resíduos à frente de cada haste, operado à profundidade média de 0,18 m, seguida de uma gradagem niveladora, efetuada com a mesma grade empregada após a aração, e (c) semeadura direta - semeadura das culturas dir retamente no solo, efetuada por meio da utilização de semeadoras-adubadoras específicas a cada cultura.

As classes de declividade do solo foram: (a) 00,04 $\mathrm{m} \mathrm{m}^{-1}$, (b) 0, 04-0,08 $\mathrm{m} \mathrm{m}^{-1} \mathrm{e}$ (c) 0,08-0,12 $\mathrm{m} \mathrm{m}^{-1}$, com gradientes médios de, respectivamente, 0,035 ; 0,065 e $0,095 \mathrm{~m} \mathrm{~m}^{-1}$.

Os níveis de fertilidade do solo foram: (a) solo com fertilidade atual (sem aplicação de calcário e adubo) e (b) solo com fertilidade corrigida (com aplicação única de cal cário no início do experimento e de adubo - N, P eK - a cada plantio).

Em maio de 1994, com base na análise de solo feita em laboratório da RedeOficial de Laboratórios de Análise de Solo do Rio Grande do Sul e Santa Catarina (ROLAS-RS/SC), foi realizada a correção da acidez do solo, aplicando-se superficialmente $5 \mathrm{Mg} \mathrm{ha}^{-1}$ de cal cário dol omítico, a lanço, seguido da incor poração do cal cário ao sol o por meio de preparo do sol o convencional (uma aração e duas gradagens), em toda a área experimental, exceto nas parcelas da classe de declividade intermediária, destinadas a receber, mais tarde, no período de primavera-verão, os tratamentos de preparo do solo sob a condição "solo com fertilidade atual". Logo a seguir, foi implantada a cultura da aveia preta (Avena strigosa, S.) - safra de 1994, com o objetivo de uniformizar a área experimental e proporcionar cobertura ao solo.

Em outubro de 1994, após a colheita da aveia preta, foram instaladas, em cada classe de declividade, as três parcelas principais de preparo do solo, com $24 \mathrm{~m}$ de comprimento, no sentido do declive, por $50 \mathrm{~m}$ de largura, correspondendo cada uma delas a um método de preparo do solo. Cada parcela de preparo, por sua vez, foi dividida ao meio, no sentido do declive, para estabelecer as duas condições (níveis) de fertilidade do solo pretendidas, a saber: "solo com fertilidade atual" e "solo com fertilidade corrigida", como já mencionado. Logo a seguir, foram instaladas as unidades experimentais propriamente ditas (parcelas de erosão), com dimensões efetivas de $4 \mathrm{~m}$ de largura por $21 \mathrm{~m}$ de comprimento, no sentido do declive, destinadas à avaliação das perdas de solo e água por erosão hídrica, sendo as operações de preparo do solo e semeadura realizadas todas transversalmente ao declive, exceto na parcela do tratamento-testemunha ou "parcela-padrão", a qual foi preparada no sentido da pendente, conformeexplicadoabaixo. Observaramse 13 parcelas de erosão, cada uma delas correspondendo a um tratamento, sem repetição, de acordo com as limitações, tais como: distância do experimento da sede detrabalho, área física, pessoal, recursos financeiros e dificuldade do trabal ho.
Nas classes de declividade de 0-0,04 e 0,08$0,12 \mathrm{~m} \mathrm{~m}^{-1}$, as parcelas de erosão foram instaladas somente na condição "sol o com fertilidade corrigida", porém contemplando os três métodos de preparo do solo, enquanto, na classe de declividade de 0,04$0,08 \mathrm{~m} \mathrm{~m}^{-1}$, foram também instaladas na condição "solo com fertilidadeatual". Na classe de declividade intermediária, foi ainda instalada a parcela-padrão ou testemunha, porém com as dimensões padrões de 3,5 m delargura por 22 m de comprimento, sendo preparada convencionalmente (uma aração e duas gradagens), no sentido do declive, a cada implantação de uma cultura, e mantida permanentemente descoberta esem crosta (Wischmeier \& Smith, 1978).

Nos tratamentos associados à condição "sol o com fertilidade corrigida", os adubos ( $\mathrm{N}, \mathrm{P}_{2} \mathrm{O}_{5}$ e $\mathrm{K}_{2} \mathrm{O}$ ) foram aplicados antes do preparo do solo e da implantação das culturas, manualmente, a lanço, nas quantidades indicadas pelos resultados da análise de solo feita em laboratório (ROLAS-RS/SC).

A aveia preta foi semeada em 20/05/1994 e $11 / 05 / 1995$, sendo col hida, para grãos, em 26/10/1994 e 19/10/1995, respectivamente. A soja foi semeada em 8/12/1994 e 30/12/1995, sendo col hida em 6/04/ 1995 e 7/05/1996, respectivamente. Tais culturas foram semeadas, sempre, transversalmente ao declive.

A semeadura da aveia preta foi efetuada por meio de uma semeadora defluxo contínuo, de arrasto, com 13 linhas, espaçadas de 0,18 m, na profundidade de $0,03 \mathrm{~m}$. A semeadora possuía sulcador tipo discos duplos para sementes e roda compactadora em formato de "V".

Para a semeadura da soja, foi empregada uma semeadora de precisão, de arrasto, com cincolinhas espaçadas de 0,45 m. A semeadura possuía um disco de corte para resíduos, sulcador para sementes tipo discos duplos e roda compactadora em formato de "V". Na semeadura direta, utilizou-se sulcador de adubo tipo facão para a abertura do sulco. Nos demais métodos de preparo do solo, tal sulco foi aberto com sulcador do tipo discos duplos. A profundidade média de trabal ho do órgão sulcador foi de $0,06 \mathrm{~m}$.

O controle de plantas invasoras foi efetuado por meio da aplicação de herbicidas de contato, para a aveia, e seletivo, para a soja, empregando-se um pulverizador de barras tratorizado. A colheita das culturas foi efetuada por meio de colhedora autopropelida degrãos, dotada de picador-distribuidor de palhas.

Após a colheita, antes dos preparos primários (aração e escarificação) e depois dos preparos secundários e, ou, de semeadura das culturas, foram col etadas amostras dos resíduos culturais presentes na superfície do sol o, para quantificação da produção de matéria seca (em estufa com circulação forçada 
de ar, a $60^{\circ} \mathrm{C}$ ). Nessas mesmas ocasiões, foram tomados dois diapositivos por parcela, com a finalidade de avaliar a percentagem de cobertura do solo pel o método fotográfico (Laflen et al., 1981).

A delimitação, superior elateral, das parcelas de erosão foi feita, construindo-se, com enxada manual, pequenos camalhões de solo, logo após a semeadura das culturas, com aproximadamente $0,20 \mathrm{~m}$ de altura e 0,30 m de base, tendo sido compactados por meio de pisotei o com os pés e pressão efetuada com a enxada, para evitar seu desmoronamento pela ação das chuvas, bem como a entrada de água de fora para dentro e a saída dela de dentro para fora da parcela. Esta forma de delimitação das parcelas de erosão permitiu que os tratos culturais, posteriores à semeadura, pudessem ser executados normal mente, sem restrições ao uso regular de trator eimplementos agrícolas. Na parcela-padrão (testemunha), em que não houve cultivo, tal delimitação foi efetuada com chapas galvanizadas, cravadas nosol oà profundidade média de $0,10 \mathrm{~m}$.

$\mathrm{Na}$ extremidade inferior de cada parcela de erosão, foi instalado um sistema coletor de enxurrada, constituído por uma calha metálica, a qual recebia, e conduzia, para um tubo de PVC com $0,10 \mathrm{~m}$ de diâmetro e 4,0 m de comprimento, 0 material erodido proveniente das parcelas até os tanques coletores (um de decantação e um de suspensão), de amianto, com capacidade de $1.000 \mathrm{~L}$ cada um, localizados numa trincheira aberta um pouco abaixo das parcelas.

A pós a ocorrência de uma chuva erosiva, retiravasea maior quantidadepossível do sedimento "grosso" existente no tanque de decantação, pesava-se tal material eretirava-se dele uma amostra. A seguir, media-sea al tura da água de enxurrada nos tanques coletores (de decantação e de suspensão), homogeneizava-se manualmente o material erodido (água de enxurrada e sedimento "fino") e retiravamse dele duas amostras. As amostras com os sedimentos "grosso" (partículas mais grosseiras de solo) e "fino" (partículas mais finas de sol o eágua de enxurrada), col etadas em campo, eram levadas ao laboratório, para determinar a concentração de sedimento na enxurrada, e para calcular, posteriormente, as quantidades de solo e água perdidas por erosão, em cada chuva erosiva, em cada tratamento, seguindo o procedimento descrito por Cogo (1978). As col etas para as aval iações de erosão foram realizadas durante o ciclo da cultura da soja em duas safras (1994/95 e 1995/96) e da aveia preta em uma safra (1995), perfazendo um período total de avaliação de 1,5 ano (dezembro de 1994 a maio de 1996).

Próximo à área experimental, instalou-se um pluviógrafo para registrar a distribuição temporal da quantidade das chuvas ocorridas, para posteriores cál culos da intensidade e erosividade, tendo sido utilizado o índice $\mathrm{EI}_{30}$ (Wischmeier, 1959), para caracterizar o último fator, considerado adequado para estimar o potencial erosivo das chuvas para a região onde foi realizada a presente pesquisa (M orais et al., 1988).

Em decorrência da variação nos gradientes de declive entre as parcelas de erosão, mesmo dentro de uma mesma classe de declividade do terreno, os resultados observados de perda de solo foram ajustados para os gradientes de declive médios de cada classe, a saber: 0,035; 0,065 e 0,095 $\mathrm{m} \mathrm{m}^{-1}$, respectivamente, para as classes de declividade de 0-0,04 $\mathrm{m} \mathrm{m}^{-1}, 0,04-0,08 \mathrm{~m} \mathrm{~m}^{-1} \mathrm{e} 0,08-0,12 \mathrm{~m} \mathrm{~m}^{-1}$, bem como para o comprimento de rampa padrão de $22 \mathrm{~m}$. Os resultados assim apresentados permitirão, após novos ajustes dos dados de perda de solo para a declividade-padrão de $0,09 \mathrm{~m} \mathrm{~m}^{-1}$, efetuar comparações diretas com os dados de erosão de outras pesquisas que, também, tenham usado as características da parcela-padrão ou unitária, definida por Wischmeier \& Smith (1978). Os ajustes de dados neste trabal ho foram feitos com base no método desenvolvido por estes últimos autores, eseu melhor detal hamento pode ser encontrado em Cogo (1981).

\section{RESULTADOS E DISCUSSÃO}

\section{Quantidade de resíduos culturais e equivalente percentagem de cobertura do solo}

Os resultados dessas variáveis encontram-se no quadro 1. Observa-se que, antes do preparo do solo (AP), os menores valores de massa seca $\left(60^{\circ} \mathrm{C}\right)$ dos resíduos culturais e equivalentes percentagens de cobertura foram encontrados nos tratamentos estabelecidos na condição "solo com fertilidade atual", independentemente da cultura e do método de preparo e, ou, de semeadura utilizado, o que é lógico. Entretanto, tais diferenças causadas pelos níveis de fertilidade do solo, em termos de massa, foram mais acentuadas para o resíduo cultural da soja, a qual produziu maior quantidade de resíduos (até o dobro) do que a aveia preta, enquanto, em termos de percentagem de cobertura do solo, as diferenças foram mais acentuadas para o resíduo cultural da aveia preta.

Após as operações de preparo do solo e, ou, de semeadura (DS), a massa seca de resíduos culturais remanescente na superfície do sol o esua equivalente percentagem de cobertura foram reduzidas, em média, em 93, 76 e $17 \%$, respectivamente nos preparos convencional, reduzido esemeadura direta, em relação aos valores existentes antes de tais operações, independentemente do tipo de resíduo cultural enível defertilidade do solo. Tais reduções podem ser explicadas pela atuação diferenciada dos instrumentos de preparo utilizados. 
Resultados semel hantes foram encontrados por Cogo (1981) e Lopes et al. (1987), podendo, no entanto, algumas diferenças entre tipos de resíduo cultural serem devidas a diferenças na densidade, morfologia e tamanho das peças constituintes dos mesmos, dependendo o último fator do grau de fragmentação dos resíduos pelo picador de palhas utilizado na colhedora.

\section{Erosividade das chuvas}

O potencial de erosão hídrica de determinado local ou região pode ser caracterizado por meio da avaliação da erosividade das chuvas e sua distribuição temporal. Tais resultados, obtidos neste estudo, estão apresentados na figura 1 . No período de aval iação da erosão (1,5 ano - dezembro de 1994 a maio de 1996), o val or absoluto cal culado do índice de erosividade $\left(\mathrm{EI}_{30}\right.$ ) foi de $10.236 \mathrm{MJ} \mathrm{mm} \mathrm{ha-1} \mathrm{h}^{-1}$, com a distribuição relativa temporal acumulada mostrada na figura 1 . Observa-se claramentequea erosividade das chuvas praticamente concentrou-se em uma única época do ano, repetidamente, em 1995 e 1996, nos seus três primeiros meses (janeiro a março), com um valor acumulado nestes duplos períodos de, aproximadamente, $70 \%$ do total ocorrido durante o período experimental. Em que pese o pequeno tempo de avaliação da erosividade neste estudo, pode-se, em princípio, dizer que o período de alto risco de erosão para o local em questão é o compreendido entre janei ro e março.

Dependendo da época de semeadura das culturas do período de primavera-verão, principalmente quando ocorre atraso, tal período pode coincidir com oinício de desenvol vimento das cul turas estabel ecidas nestas associadas estações. I sto aumenta mais ainda o risco de erosão, especial mente quando se utilizam preparos de solo que o mobilizam muito, como o convencional, ficando o sol o pouco protegi do da ação das chuvas e de suas enxurradas associadas, tanto pelas plantas, quanto pelos resíduos culturais. $\mathrm{O}$ que pode acontecer, porém não desejado, nesses casos, é a coincidência do período de alto risco de erosão (período de el evada erosividade das chuvas) com o período crítico de erosão da cultura (período de pouca proteção ao solo, propiciada pelas plantas em crescimento), quando então ocorrem as grandes erosões. Há, pois, que atentar-se para não haver coincidência desses períodos, especialmente quando neles é também escassa a cobertura do solo por resíduos culturais.

\section{Perdas de solo e água de acordo com os métodos de preparo e classes de declividade do solo}

Os resultados dessas variáveis estão apresentados no quadro 2. Tomando por base a cultura da soja, a qual foi avaliada em dois ciclos, verifica-se que as perdas de solo e água variaram muito entre os anos agrícol as de 1994/95 e 1995/96, de acordo com a variação observada nos valores absolutos (Quadro 2) e na distribuição da erosividade das chuvas (Figura 1), em todos os tratamentos avaliados, com os maiores valores ocorrendo no segundo ano de cultivo desta cultura (safra de 1995/ 96). Em tal safra, registrou-se, aproximadamente, $45 \%$ da erosividade total ocorrida no período de estudo. Na safra de 1994/95, registrou-se, aproximadamente, $35 \%$ da erosividade total. A maior erosividade das chuvas observada no período relativo às culturas de primavera-verão coincidiu com os resultados obtidos por Cogo et al. (1978) e Lima et al. (1992).

E mbora a erosividade das chuvas no ciclo da soja da safra de 1995/96 tenha sido apenas $10 \%$ superior

Quadro 1. Massa seca $\left(60^{\circ} \mathrm{C}\right)$ de resíduos culturais superficiais de aveia preta e soja e equivalente percentagem de cobertura do solo, após a colheita e antes do preparo de solo (AP) e depois da semeadura (DS), nos tratamentos de preparo e níveis de fertilidade do solo, na classe de declividade de $0,04-0,08 \mathrm{~m} \mathrm{~m}^{-1}$

\begin{tabular}{|c|c|c|c|c|c|c|c|c|}
\hline \multirow{3}{*}{$\begin{array}{l}\text { Preparo do solo e nível } \\
\text { de fertilidade }\end{array}$} & \multicolumn{4}{|c|}{ Massa de resíduo } & \multicolumn{4}{|c|}{ Cobertura do solo } \\
\hline & \multicolumn{2}{|c|}{ Aveia preta } & \multicolumn{2}{|c|}{ Soja } & \multicolumn{2}{|c|}{ Aveia preta } & \multicolumn{2}{|c|}{ Soja } \\
\hline & $\mathbf{A P}$ & DS & $\mathbf{A P}$ & DS & $\mathbf{A P}$ & DS & $\mathbf{A P}$ & DS \\
\hline & \multicolumn{4}{|c|}{ - kg ha-1 } & \multicolumn{4}{|c|}{ — } \\
\hline $\begin{array}{l}\text { Semeadura direta, sfa(1) } \\
\text { Semeadura direta, } \operatorname{sfc}^{(2)}\end{array}$ & $\begin{array}{l}1.803 \\
2.281\end{array}$ & $\begin{array}{l}1.581 \\
2.045\end{array}$ & $\begin{array}{l}3.210 \\
5.326\end{array}$ & $\begin{array}{l}2.736 \\
3.717\end{array}$ & $\begin{array}{l}87 \\
95\end{array}$ & $\begin{array}{l}72 \\
75\end{array}$ & $\begin{array}{l}83 \\
92\end{array}$ & $\begin{array}{l}60 \\
74\end{array}$ \\
\hline $\begin{array}{l}\text { Reduzido, sfa } \\
\text { Reduzido, sfc }\end{array}$ & $\begin{array}{l}2.075 \\
2.185\end{array}$ & $\begin{array}{l}676 \\
653\end{array}$ & $\begin{array}{l}3.741 \\
4.303\end{array}$ & $\begin{array}{l}668 \\
742\end{array}$ & $\begin{array}{l}76 \\
93\end{array}$ & $\begin{array}{l}24 \\
27\end{array}$ & $\begin{array}{l}89 \\
90\end{array}$ & $\begin{array}{l}15 \\
24\end{array}$ \\
\hline $\begin{array}{l}\text { Convencional, sfa } \\
\text { Convencional, sfc }\end{array}$ & $\begin{array}{l}2.039 \\
2.277\end{array}$ & $\begin{array}{l}179 \\
176\end{array}$ & $\begin{array}{l}2.923 \\
4.373\end{array}$ & $\begin{array}{l}139 \\
270\end{array}$ & $\begin{array}{l}66 \\
94\end{array}$ & $\begin{array}{r}9 \\
11\end{array}$ & $\begin{array}{l}88 \\
90\end{array}$ & $\begin{array}{l}6 \\
9\end{array}$ \\
\hline
\end{tabular}

${ }^{(1)}$ sfa - solo com fertilidade atual. ${ }^{(2)}$ sfc - solo com fertilidade corrigida. 


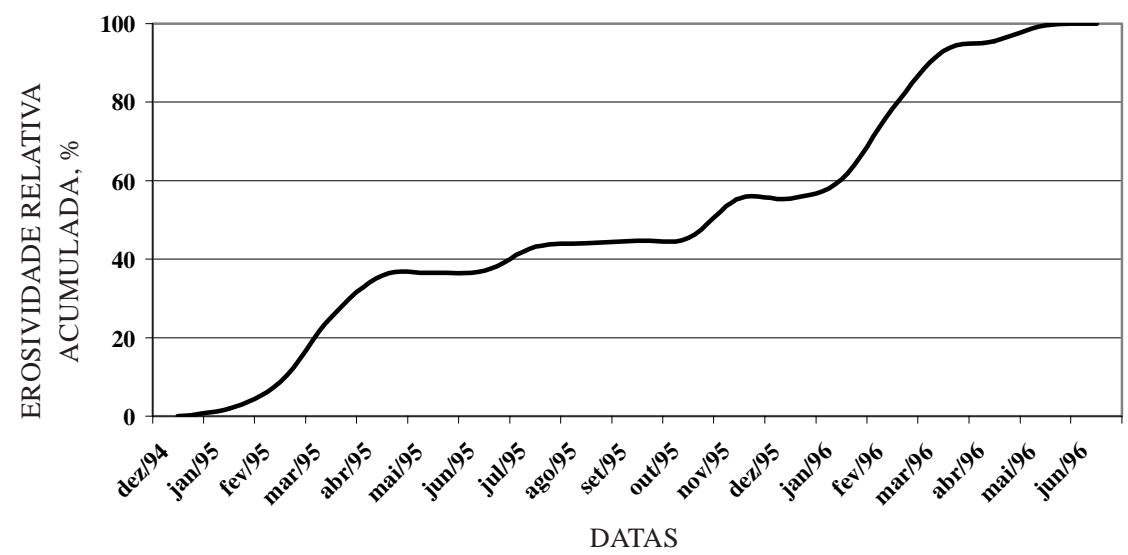

Figura 1. Distribuição relativa acumulada temporal da erosividade (índice $\mathrm{EI}_{30}$ ) das chuvas no período experimental (ciclos culturais da soja avaliados para erosão: 8/12/94 a 6/04/95 e 30/12/95 a 7/05/96; ciclo cultural da aveia preta avaliado para erosão: 11/05/95 a 19/10/95).

à da safra de 1994/95, o aumento nas perdas de sol o foi muito maior, independentemente do método de preparo do solo e classe de declividade do terreno, chegando, até, a $800 \%$ (Quadro 2). Isto pode ser explicado pelas diferenças na distribuição temporal da erosividade das chuvas e no estádio de crescimento das culturas.

Na safra da soja de 1994/95, a erosividade das chuvas concentrou-se mais no período entre os 60 dias após a semeadura ea col heita, correspondendo a $75 \%$ do total da erosividade ocorrida no ciclo da cultura (Figura 1). Nesta safra, no entanto, no período referido, a cultura da soja já estava plenamente estabel ecida e propiciando ampla e boa cobertura ao solo.

Por outrolado, na safra de 1995/96, a erosividade das chuvas concentrou-se mais nos primeiros 30 dias após a semeadura da soja, correspondendo, apenas, a $40 \%$ do total ocorrido no ciclo da cultura (contra os $75 \%$ na safra de 1994/95), porém, desta vez, ocorrendo quando o sol o se encontrava ainda muito pouco protegido pela cultura, o que favoreceu muito as perdas de solo e água por erosão, especialmente no preparo convencional. Estes resultados evidenciam a importância do suprimento de elevada cobertura vegetal ao solo, seja por plantas, seja por seus resíduos, naqueles períodos de maior erosividade das chuvas, para o eficaz controle da erosão hídrica (Wischmeier \& Smith, 1978).

Em relação à cultura da aveia preta, avaliada apenas em um ciclo (safra de 1995), no período de outono-inverno, verifica-se, no quadro 2, que as perdas de solo e água foram muito baixas, comparadas às da cultura da soja, em todos os tratamentos estudados. I sto deveu-seà erosividade muito baixa das chuvas ocorrida durante o ciclo cultural desta cultura (Figura 1), correspondendo, apenas, a $20 \%$ do total ocorrido durante o período experimental, além do que esta relativamente baixa quantidade de energia erosiva atuou no solo entre os 60 dias após a semeadura e a col heita, quando a cultura já propiciava ampla e boa cobertura ao solo.

Em comparação à erosão verificada na parcelapadrão, preparada convencionalmente no sentido do declive e mantida continuamente descoberta, as culturas da soja eaveia preta, também estabel ecidas sob preparo convencional, porém transversalmente ao declive, reduziram, em média, em $80 \%$ as perdas de solo e em $50 \%$ as perdas de água (Quadro 2). O efeito combinado de redução da erosão dos fatores cobertura vegetal e preparo do sol o esemeadura em contorno foi mais pronunciado durante o ciclo da cultura da aveia do que do da soja, podendo este fato ser explicado pela distribuição temporal acumulada da erosividade das chuvas diferenciadas nos ciclos destas culturas (Figura 1), por possíveis diferenças no teor de água no solo antecedente às chuvas entre as duas épocas do ano e, certamente, pelas diferenças inerentes ao tipo de cultura, tais como: sistema radicular, espaçamento, população e rapidez de crescimento das plantas.

O tratamento-testemunha (parcela-padrão) também apresentou perdas por erosão bem menores no período de primavera-verão de 1994/95 do que no de 1995/96 (Quadro 2). I sto pode ser atribuído à erosividade das chuvas um pouco mais elevada no segundo período de avaliação, mas, provavel mente, el efoi devido mais ao efeito do uso anterior da terra (efeitoresidual), muito presenteno primeiro período deavaliação e pouco no segundo. I sto porque a área experimental para esta pesquisa vinha por anos sendo cultivada com culturas anuais, além de apresentar alto grau de infestação com plantas invasoras noinício do experimento, dominantemente do tipo gramíneas. E isto pode ter influenciado muito, e positivamente, a estrutura do solo, 
conseqüentementesua erodibilidade, diminuindo-a, comparada à condição física do solo existente no segundo período de observação, quando o efeito residual do uso da terra certamente já havia diminuído muito, o que pode ter favorecido bastante as perdas por erosão no segundo ano agrícola.

Dentre os métodos de preparo do solo avaliados, o sem preparo ou semeadura direta foi o mais eficaz no controle da erosão, independentemente das dasses de declividade (Quadro 2). Na menor classe deded ividade, as perdas de sol oforam relativamente baixas e semelhantes entre os preparos (o maior val or observado no preparo reduzido foi considerado estranho, porém não pode ser explicado). No entanto, nas classes de declividade mais elevadas, as diferenças nas perdas de solo entre os preparos cresceram consideravelmente, porém de forma diferenciada, sendo o efeito mais pronunciado no preparo convencional, intermediário no preparo reduzido e menor na semeadura direta. O aumento da er osão com o aumento da declividade do terreno se deve ao aumento da capacidade erosiva da enxurrada nos declives mais acentuados, decorrente do aumento de sua velocidade, especialmente quando osolo éintensamente mobilizadoe apresenta baixa cobertura superficial, ficando sujeito à formação de sulcos, selos e, ou, crostas, os quais dificultam a infiltração de água no sol o e favorecem o escoamento superficial.
Nas classes de declividade mais elevadas, a eficácia da semeadura direta na redução da perda de solo foi, em média, 90 e $70 \%$, respectivamente, em relação ao preparo convencional e reduzido (Quadro 2), justificada tanto pela presença de resíduos culturais na superfície do terreno, que lhe proporcionaram uma cobertura média de $75 \%$ após a semeadura (Quadro 1), quanto pela reconsolidação da superfície do solo, dada a ausência de preparo neste tratamento. No preparo convencional e no reduzido, a cobertura do sol o por resíduos culturais foi, respectivamente, em média, de 9 e $24 \%$ (Quadro 1), com as perdas de solo no último sendo $65 \%$ menores do que no primeiro, na média das classes de declividade (Quadro 2). Este fato pode ser atribuído aos diferentes graus de proteção do solo propiciados pelas restevas das culturas anteriores, aliado à ação diferenciada dos instrumentos de preparo utilizados, onde o preparo reduzido, embora com menor grau de mobilização do solo do que o convencional, visivelmente apresentava maior rugosidadesuperficial do solo. I stotambém concorreu para que o preparo reduzido tendesse a apresentar as menores perdas de água no experimento, na média dos tratamentos estudados (Quadro 2).

Tomando por base os dados de perda de solo da parcela-padrão (ajustados para a declividade de 0,09 $\mathrm{m} \mathrm{m}^{-1}$ - o comprimento de rampa já era de $22 \mathrm{~m}$, o que dispensou o ajuste para esta variável),

Quadro 2. Perdas de solo e água por erosão, por ciclo cultural e no somatório dos ciclos, consi derando os métodos de preparo e classes de declividade do solo, na condição "solo com fertilidade corrigida"

\begin{tabular}{|c|c|c|c|c|c|c|c|c|}
\hline \multirow{2}{*}{$\begin{array}{c}\text { Cultura - Safra } \\
\text { Chuva }(\mathrm{mm})^{(1)} \\
{\text { E I } 30^{(2)}}^{(2)} \\
\text { Preparo do solo(3) }\end{array}$} & \multicolumn{2}{|c|}{$\begin{array}{c}\text { Soja }(1994 / 95) \\
545 \\
3.798\end{array}$} & \multicolumn{2}{|c|}{$\begin{array}{c}\text { Aveia (1995) } \\
455 \\
1.800\end{array}$} & \multicolumn{2}{|c|}{$\begin{array}{c}\text { Soja }(1995 / 96) \\
726 \\
4.638\end{array}$} & \multicolumn{2}{|c|}{$\begin{array}{r}\text { Total } \\
1.726 \\
10.235\end{array}$} \\
\hline & Solo & Água & Solo & Água & Solo & Água & Solo & Água \\
\hline & $\mathrm{kg} \mathrm{ha}^{-1}$ & $\mathrm{~mm}$ & kg ha-1 & $\mathrm{mm}$ & kg ha-1 & $\mathrm{mm}$ & $\mathrm{kg} \mathrm{ha}^{-1}$ & $\mathrm{~mm}$ \\
\hline & \multicolumn{8}{|c|}{ Declividade de $0-0,04 \mathrm{~m} \mathrm{~m}^{-1}$} \\
\hline $\begin{array}{l}\text { Semeadura direta } \\
\text { Reduzido } \\
\text { Convencional }\end{array}$ & $\begin{array}{l}188 \\
543 \\
473\end{array}$ & $\begin{array}{r}4,3 \\
7,9 \\
11,0\end{array}$ & $\begin{array}{l}111 \\
163 \\
124\end{array}$ & $\begin{array}{l}3,2 \\
2,8 \\
1,8\end{array}$ & $\begin{array}{r}679 \\
2.068 \\
616\end{array}$ & $\begin{array}{l}30,3 \\
20,2 \\
31,2\end{array}$ & $\begin{array}{r}978 \\
2.774 \\
1.213\end{array}$ & $\begin{array}{l}37,8 \\
30,9 \\
44,0\end{array}$ \\
\hline Convencional & \multicolumn{8}{|c|}{ Declividade de $0,04-0,08 \mathrm{~m} \mathrm{~m}^{-1}$} \\
\hline $\begin{array}{l}\text { Semeadura direta } \\
\text { Reduzido } \\
\text { Convencional }\end{array}$ & $\begin{array}{r}273 \\
412 \\
1.715\end{array}$ & $\begin{array}{r}4,6 \\
6,0 \\
12,1\end{array}$ & $\begin{array}{r}115 \\
142 \\
87\end{array}$ & $\begin{array}{l}3,3 \\
2,8 \\
1,8\end{array}$ & $\begin{array}{r}649 \\
3.839 \\
9.770\end{array}$ & $\begin{array}{l}36,8 \\
41,8 \\
43,6\end{array}$ & $\begin{array}{r}1.037 \\
4.393 \\
11.572\end{array}$ & $\begin{array}{l}44,7 \\
50,6 \\
57,5\end{array}$ \\
\hline \multirow[t]{2}{*}{ Parcela-padrão } & 7.913 & 34,8 & 1.085 & 12,4 & 50.287 & 78,8 & 59.285 & 121,0 \\
\hline & \multicolumn{8}{|c|}{ Declividade de $0,08-0,12 \mathrm{~m} \mathrm{~m}^{-1}$} \\
\hline $\begin{array}{l}\text { Semeadura direta } \\
\text { Reduzido } \\
\text { Convencional }\end{array}$ & $\begin{array}{r}216 \\
799 \\
1.427\end{array}$ & $\begin{array}{r}7,4 \\
4,5 \\
11,7\end{array}$ & $\begin{array}{l}156 \\
147 \\
127\end{array}$ & $\begin{array}{l}2,2 \\
2,6 \\
2,9\end{array}$ & $\begin{array}{r}1.160 \\
3.229 \\
11.497\end{array}$ & $\begin{array}{l}35,4 \\
25,1 \\
46,9\end{array}$ & $\begin{array}{r}1.532 \\
4.175 \\
13.051\end{array}$ & $\begin{array}{l}45,0 \\
32,2 \\
61,5\end{array}$ \\
\hline
\end{tabular}


col etados durante o período de avaliação da erosão (1,5 ano), o valor médio anual calculado do fator $\mathrm{K}$ erodibilidadedosolofoi de 0,0091 t ha $\mathrm{h} \mathrm{MJ}{ }^{-1} \mathrm{~mm}^{-1} \mathrm{ha}^{-1}$, o qual pode ser considerado muito baixo, porém consistente para solos do tipo latossólico, como o utilizado no experimento, cuja microagregação e mineralogia próprias conferem-Ihes elevada resistência à ação dos agentes erosivos.

Em relação às perdas de água, elas foram bem menos influenciadas pelos métodos de preparo do que as perdas desolo (Quadro 2), independentemente das classes de declividade, concordando com trabal hos de Cogo (1981), Bertol et al . (1989) eL evien et al. (1990). As diferenças nas perdas deágua foram pequenas dentro de uma mesma classe de dedividade, mas mostraram tendência de serem um pouco maiores no preparo convencional e um pouco menores no preparo reduzido, ficando a semeadura direta em posição intermediária.

Considerando o total de chuva precipitado no período experimental, as perdas deágua por erosão, sob cultivo, foram, de modo geral, muito baixas (menores do que $4 \%$ ), porém próximas às obtidas em outros estudos em que foi utilizado o mesmo tipo desolo (Rio Grande do Sul, 1985), nos quais o preparo ea semeadura foram efetuados no sentido do declive.

Embora o tratamento-testemunha, ou parcelapadrão (convencional sem cultivo, realizado no sentido do declive), tenha apresentado perda deágua duas vezes maiores do que o tratamento convencional com cultivo (com a presença das culturas de aveia preta e soja e estabelecido em contorno), tal perda pode também ser considerada ainda muito baixa (aproximadamenteapenas $7 \%$ dototal precipitado).
Vale ressaltar o fato de que as perdas anuais de solo verificadas com o sistema de produção aveia preta-soja em preparo convencional, nos declives superiores a $0,04 \mathrm{~m} \mathrm{~m}^{-1}$ (ao redor de $12,5 \mathrm{Mg} \mathrm{ha}^{-1} \mathrm{em}$ 1,5 ano, em média), praticamenteatingiram olimite tolerável para o tipo de sol o utilizado no estudo (13 a $15 \mathrm{Mg} \mathrm{ha}^{-1} \mathrm{ano}^{-1}$, segundo Bertoni \& Lombardi Neto, 1993 e Bertol \& Almeida, 2000), já no curto comprimento de rampa de $21 \mathrm{~m}$ utilizado no experimento, mesmo com as operações de preparo do solo e semeadura tendo sido realizadas em contorno, efetuada a mel horia da fertilidade do solo e ser este um sol o relativamente muito resistente à erosão hídrica.

Mesmo as perdas relativamente baixas de solo verificadas no preparo reduzido (ao redor $4,2 \mathrm{Mg} \mathrm{ha}^{-1}$ em 1,5 ano, em média) e na semeadura direta (ao redor de 1,2 $\mathrm{Mg} \mathrm{ha}^{-1}$ em 1,5 ano, em média), também em declives superiores a 0,04 $\mathrm{m} \mathrm{m}^{-1}$, podem ser consideradas preocupantes, tendo em vista o curto comprimento de rampa de $21 \mathrm{~m}$ do qual elas provieram (Quadros 2 e 3).

Deduz-se desses fatos a necessidade de dar-se muita atenção às práticas conservacionistas de suporte, principalmente os terraços, quando as lavouras são estabel ecidas em declives I ongos e, ou, inclinados, para garantir o adequado controle da erosão e, ao mesmo tempo, disciplinar o movimento das águas de escoamento superficial ou enxurrada.

\section{Perdas de solo e água de acordo com os níveis de fertilidade do solo}

O efeito da fertilidade do sol o sobre a erosão pode ser verificado pela análise dos resultados apresentados

Quadro 3. Perdas de solo e água por erosão nas diferentes safras das culturas de aveia preta e soja, considerando os métodos de preparo e níveis de fertilidade do solo, na classe de declividade 0,04 $0,08 \mathrm{~m} \mathrm{~m}^{-1}$

\begin{tabular}{|c|c|c|c|c|c|c|}
\hline \multirow{2}{*}{ Cultura - Safra } & \multicolumn{2}{|c|}{ Semeadura direta } & \multicolumn{2}{|c|}{ Preparo reduzido } & \multicolumn{2}{|c|}{ Preparo convencional } \\
\hline & $\operatorname{sfc}^{(1)}$ & $\operatorname{sfa}(2)$ & sfc & sfa & sfc & sfa \\
\hline & \multicolumn{6}{|c|}{ Perda de solo, kg ha-1 } \\
\hline $\begin{array}{l}\text { Soja - 1994/95 } \\
\text { Aveia - 1995 } \\
\text { Soja - 1995/96 }\end{array}$ & $\begin{array}{l}273 \\
115 \\
649\end{array}$ & $\begin{array}{r}566 \\
488 \\
1.722\end{array}$ & $\begin{array}{r}412 \\
142 \\
3.839\end{array}$ & $\begin{array}{r}545 \\
136 \\
1.953\end{array}$ & $\begin{array}{r}1.715 \\
87 \\
9.770\end{array}$ & $\begin{array}{r}5.741 \\
748 \\
24.450\end{array}$ \\
\hline \multirow[t]{2}{*}{ Total } & 1.037 & 2.776 & 4.393 & 2.634 & 11.572 & 30.939 \\
\hline & \multicolumn{6}{|c|}{ Perda de água, mm } \\
\hline $\begin{array}{l}\text { Soja - 1994/95 } \\
\text { Aveia - 1995 } \\
\text { Soja - 1995/96 }\end{array}$ & $\begin{array}{r}4,6 \\
3,3 \\
36,8\end{array}$ & $\begin{array}{r}5,4 \\
12,2 \\
47,2\end{array}$ & $\begin{array}{r}6,0 \\
2,8 \\
41,8\end{array}$ & $\begin{array}{r}6,4 \\
3,7 \\
34,1\end{array}$ & $\begin{array}{r}12,1 \\
1,8 \\
43,6\end{array}$ & $\begin{array}{r}17,2 \\
6,0 \\
46,9\end{array}$ \\
\hline Total $(\%)^{(3)}$ & 2,6 & 3,8 & 2,9 & 2,6 & 3,3 & 4,1 \\
\hline
\end{tabular}

(1) Sol o com fertilidade corrigida. ${ }^{(2)}$ Solo com fertilidade atual. ${ }^{(3)}$ Perda de água na forma de enxurrada, em percentagem da chuva, relativo ao total precipitado no período. 
no quadro 3. É evidente a maior erosão sob a condição "sol o com fertilidade atual", especialmente em relação às perdas de sol o, as quais aumentaram, aproximadamente, 200 \%, em relação àquelas verificadas sob a condição "solo com fertilidade corrigida", tanto na semeadura direta, quanto no preparo convencional (o preparo reduzido apresentou valor estranho, o qual não pode ser explicado), apesar da grande diferença nos valores absolutos de tais perdas nesses preparos. I sto pode ser facilmente explicado, de modo indireto, pela grande influência que a fertilidade do solo tem, tanto na produção defitomassa da parte aérea das culturas e, conseqüentemente dos resíduos culturais (Quadro 1), quanto de raízes, afetando muito o grau de cobertura do sol o (Quadro 1) ea qualidade de sua estrutura (agregação e resistência à desagr egação).

Deduz-se deste fato a importância de efetuar-se a calagem e a adubação do solo por ocasião do estabel ecimento de determinada cultura, nas quantidades recomendadas pela análise de sol o em laboratório, para garantir adequada fertilidade ao solo e, conseqüentemente, el evada produção de fitomassa. Sem dúvida al guma, a fertilidade do solo é um dos requerimentos básicos mais importantes na conservação do sol o e da água e, conseqüentemente, do meio ambiente.

\section{CONCLUSÕES}

1. O sol outilizado no estudo apresentou umíndice de erodibilidade muito baixo e, conseqüentemente, uma alta resistência à erosão hídrica.

2. O período do ano com o maior potencial de erosão hídrica foi o compreendido entre janeiro e março, induzindo maior erosão na cultura da soja do que na da aveia preta, independentemente dos tratamentos estudados.

3. A mel horia da fertilidade do solo pela calagem eadubação aumentou muito a produção de fitomassa aérea das culturas e, conseqüentemente, a massa de resíduos culturais, em todos os tratamentos estudados, com efeito pronunciado na redução das perdas desolo, notadamenteno preparo convencional.

4. As perdas de solo por erosão hídrica foram as mais elevadas no preparo convencional, intermediárias no preparo reduzido e mais baixas na semeadura direta, independentemente dos tratamentos estudados, enquanto as perdas de água foram todas muito baixas esimilares, mas tendendo a serem maiores no preparo convencional, intermediárias na semeadura direta e menores do preparo reduzido.

5. O aumento da perda de solo com o aumento dos val ores das classes de declividade do terreno foi maior no preparo convencional do que no preparo reduzido e na semeadura direta.
6. O sistema de produção aveia preta-soja em preparo convencional, mesmo com as operações de preparo do solo e semeadura em contorno, mel horia da fertilidade do sol o ealta resistência desteà erosão, apresentou perdas anuais de solo por erosão, em declives superiores a $0,04 \mathrm{~m} \mathrm{~m}^{-1}$, muito próximas do limite tolerável, já no curto comprimento de rampa de 21 m utilizado nas parcelas experimentais desteestudo.

\section{AGRADECIMENTOS}

À equipe técnica do Escritório Municipal da EMATER, em SantoÂngelo(RS), pel oindispensável auxílio nos trabalhos de campo; aos Professores Paulo Schneider e Carlos Alberto Bissani, do Departamento de Solos da UFRGS, pelo apoio, e à FAPERGS, pel o financiamento da pesquisa.

\section{LITE RATURA CITADA}

ALVES, A.G.C.; COGO, N.P. \& LEVIEN, R. Relações da erosão do solo com a persistência da cobertura vegetal morta. $R$. Bras. Ci. do Solo, 19:127-132, 1995.

BERTOL, I.; COGO, N.P. \& LEVIEN, R. Cobertura morta e métodos de preparo do sol o na erosão hídrica em solo com crosta. R. Bras. Ci. do Solo, 13:373-379, 1989.

BERTOL, I. Erosão hídrica em Cambissolo húmico distrófico sob diferentes preparos do solo e rotação de culturas. R. Bras. Ci. do Solo, 18:267-271, 1994.

BERTOL. I. \& ALMEIDA, J.A. Tolerância de perda de solo por erosão para os princi pais sol os do estado de Santa Catarina. R. Bras. Ci. do Solo, 24:657-668, 2000.

BERTONI, J . \& LOMBARDI NETO, F. Conservação do solo. São Paulo, Í cone, 1993. 355p.

BRASI L. Ministério da Agricultura e do Abastecimento. Empresa Nacional de Pesquisa Agropecuária. Centro Nacional de Pesquisa de Solos. Sistema Brasileiro de Classificação de Solos. Brasília, 1999. 412p.

COGO, N.P.; DREWS, C.R. \& GIANELLO, C. Índice de erosividade (valor EI30) das chuvas dos municípios de Guaíba, Ijuí e Passo Fundo. In: ENCONTRO NACIONAL DE PESQUISA SOBRE CONSERVAÇÃO DO SOLO, 2., Passo Fundo, 1978. Anais. Passo Fundo, Empresa Brasileira de Pesquisa Agropecuária, 1978. p.145-152.

COGO, N.P. Uma contribuição à metodologia de estudo das perdas por erosão em condições de chuva natural: I Sugestões gerais, medição de volume, amostragem e quantificação de sol o eágua da enxurrada. In: ENCONTRO NACIONAL DE PESQUISA SOBRE CONSERVAÇÃO DO SOLO, 2., Passo Fundo, 1978. Anais. PassoFundo, Empresa Brasileira de Pesquisa Agropecuária, 1978. p.75-97.

COGO, N.P. Effect of residue cover, tillage induced-roughness, and slope lenght on erosion and related parameters. West Lafayette, Purdue University, 1981. 346p. (Tese de Doutorado) 
ELTZ, F.L.F.; CASSOL, E.A.; GUERRA, M. \& ABRÃO, P.U.R. Perdas de solo e água por erosão em diferentes sistemas de manejo e coberturas vegetais em solo São Pedro (Podzólico Vermel ho Amarelo) sob chuva natural. R. Bras. Ci. Solo, 8:245-249, 1984.

FARIAS, A.D. \& FERREIRA, T.N. Evolução do sistema plantio direto. Inf. EMATER-RS, p.1-4, 1996. (Série Soja/Solos)

HUDSON, N.W. Soil conservation. Ithaca, Cornell University Press, 1977. 320p.

LAFLEN, J .M.; AMEMIYA, M. \& HINTZ, E.A. Measuring crop residue cover. J . Soil Water Conserv., 36:341-343, 1981.

LEVIEN, R.; COGO, N.P. \& ROCKENBACH, C.A. Erosão na cultura do milho em diferentes sistemas de cultivo anterior e métodos de preparo do solo. R. Bras. Ci. Solo, 14:73-80, 1990.

LIMA, V.S.; CASSOL, E.A. \& SEVERO, M.D.A. Determinação da erosividade das chuvas nos municípios de Ijuí e São Borja, RS, no período de 1982-1991. In: SALÃO DE I NICIAÇÃO CIENTÍ FICA, 4., Porto Alegre, 1992. Resumos. Porto Alegre, Universidade Federal do Rio Grande do Sul, 1992. v.1, p.185.

LOPES, P.R.; COGO, N.P. \& LEVIEN, R. Eficácia relativa de tipo e quantidade de resíduos culturais espalhados uniformemente sobre o solo na redução da erosão hídrica. R. Bras. Ci. Solo, 11:71-75, 1987.

MORAIS, L.F.B.; MUTTI, L.S.M. \& ELTZ, F.L.F. Índices de erosividade correlacionados com perdas de solo no Rio Grande do Sul. R. Bras. Ci. Solo, 12:281-284, 1988.
NUNES FILHO, J .; SOUSA, A.R.; MAFRA, R.C. \& J ACQUES, F.O. Efeito do preparo do solo sobre as perdas por erosão e produção de milho num Podzólico Vermelho-Amarelo eutrófico de Serra Talhada (PE). R. Bras. Ci. Solo, 11:183186, 1987.

RIO GRANDE DO SUL. Secretaria da Agricultura. Manual de Conservação do Solo. 2.ed. Porto Alegre, 1985. 228p.

SANTANA, D.P.; PEREIRA FILHO, I.A.; SANS, L.M.A.; CRUZ, J.C. \& ALVARENGA, R.C. Perda de solo e água e modificações de características de um L atossolo Vermel hoEscuro submetido a diferentes métodos de manejo. In: REUNIÃO BRASILEIRA DE MANEJ O E CONSERVAÇÃO DO SOLO E DA ÁGUA, 10., Florianópolis, 1994. Resumos. Florianópolis: SociedadeBrasileira de Ciência doSolo. 1994. 428p.

SLONEKER, L.L. \& MOLDENHAUER, W.C. Measuring the amounts of crop residue remaining after tillage. J. Soil Water Conserv., 32:231-236, 1977.

VIEIRA, M.J .; COGO, N.P. \& CASSOL, E.A. Perdas por erosão, em diferentes sistemas de preparo do solo, para a cultura da soja em condições de chuva simulada. R. Bras. Ci. Solo, 2:209-214, 1978.

WISCHMEIER, W.H. A rainfall erosion index for a universal soil loss equation. Soil Sci. Soc. Am. Proc., 23:246-249, 1959.

WISCHMEIER, W.D. \& SMITH, D.D. Predicting rainfall erosion Iosses: a guide to conservation planning. Washington, USDA, 1978. 58p. (Agriculture Handbook, 537). 